overweight/obesity. Multinomial logistic regression was used to model the relationship between oral status with underweight and overweight/obesity.

Results The mean age was 72.7 years and the prevalence of overweight/obesity was $41.4 \%$. Oral status wasn't associated with underweight. Participants who reported using prostheses in both arches with self-perceived limitation in the type or amount of food intake and subjects that rated their oral health as good were less likely to be overweight/obese.

Conclusions Our findings suggest that dental prosthesis use with self-perceived limitation in food intake is associated with overweight/obesity but not with underweight.

\section{SP1-103 THE SOCIAL EXPERIENCES OF INFERTILITY IN A RELIGIOUS AND SPIRITUAL CONTEXT: A SOCIO-EPIDEMIOLOGIAL PERSPECTIVE}

doi:10.1136/jech.2011.142976n.80

${ }^{1} \mathrm{R}$ L Roudsari, ${ }^{2} \mathrm{H}$ Allan, ${ }^{2} \mathrm{P}$ Smith. ${ }^{1}$ Department of Midwifery, Mashhad University of Medical Sciences, Mashhad, Khorasan Razavi, Iran; ${ }^{2}$ Division of Health \& Social Care, University of Surrey, Faculty of Health \& Medical Sciences, Guildford, Surrey, UK

Introduction Existing research has predominantly focused on medical, psychological, social and cultural aspects of infertility, while religious and spiritual dimensions have received little attention. This study using a socio-epidemiological perspective designed a qualitative study to explore how religion/spirituality affect social consequences of infertility.

Method The design was a grounded theory study including semi structured in-depth interviews with 30 infertile women affiliated to different denominations of Christianity (Protestantism, Catholicism, Orthodoxy) and Islam (Shiite and Sunni). Data were collected in one Iranian and two UK fertility clinics through theoretical sampling and analysed using grounded theory (Strauss \& Corbin, 2008).

Results Emerging categories included: perceived motherhood, relationship adjustment and social functioning. Religious participants viewed motherhood as a highly recommended religious value, something sacred, God's gift, respectful honour and social fulfilment. They perceived infertility as God's will, God's test, being chosen by God and an enriching experience for spiritual growth. These kinds of beliefs helped them to perceive their marital life as something granted by God which could be accepted peacefully and its outcome would be family commitment and cohesion. Their religious views on socialisation as a religious value motivated them to search reassurance through the love and care of congregation members as well as offering support to others to gain intimacy and as a consequence being liberated from social isolation caused by infertility.

Conclusion It seems that religious beliefs are influential for religious/spiritual infertile women to handle the social implications of infertility.

\section{SP1-104 CANCER MORTALITY TRENDS IN BRAZILIAN CAPITALS AND INLAND COUNTIES BETWEEN 1980 AND 2006}

doi:10.1136/jech.2011.142976n.81

${ }^{1} \mathrm{G}$ A e Silva, ${ }^{* 1} \mathrm{C}$ Gamarra, ${ }^{1} \mathrm{~V}$ Girianelli, ${ }^{2} \mathrm{~J}$ Valente. ${ }^{1}$ University of Rio de Janerio State, Rio de Janeiro, Brazil; ${ }^{2}$ Fundação Oswaldo Cruz, Rio de Janeiro, Brazil

Objective To analyse the trends in mortality for the overall and major types of cancer, by sex, in Brazil and major regions for State Capitals and inland counties between 1980 and 2006.
Methods Data were obtained from System of Mortality Information and from Brazilian Institute of Geography \& Statistics. Magnitude of death rates from overall and major types cancers were corrected adding proportional distribution of $50 \%$ of ill-defined causes of death, and standardised by age group according to Standard World Population. Trend curves for Brazil and its major regions, for State Capitals and inland counties, by sex, and were evaluated by simple linear regression.

Results Among men ascending mortality rates were observed for lung, prostate and colorectal cancers. Declining trends were seen for stomach cancer and oesophagus cancer remains stable. Among women, mortality rates for breast, lung and colorectal cancer increased, and cervical and stomach cancer declined markedly. Mortality trends varied among Brazilian major regions and exhibited distinct patterns for state capitals and inland counties.

Conclusion Correction of mortality rates, based on redistribution of ill-defined causes of death, increased the overall cancer mortality in Brazil by $10 \%$ in 1980 and $5 \%$ in 2006. Among inland counties, and different from State Capitals, no decrease or stability in trend of mortality rates was found. Worse access to health services of diagnostic and treatment for cancer and less outreach of prevention actions among populations living away from big urban centers in Brazil, may be part of the explanation for these differences.

\section{SP1-105 THE APPLICATION OF COLLABORATIVE COUNSELLING MODEL TO MANAGE STRESS AND COPING IN INFERTILE WOMEN UNDERGOING IVF: A RANDOMISED CLINICAL TRIAL}

doi:10.1136/jech.2011.142976n.82

${ }^{1} \mathrm{R}$ L Roudsari, ${ }^{1} \mathrm{M}$ Rasoulzadeh, ${ }^{2} \mathrm{~N}$ Mousavifar, ${ }^{1} \mathrm{M} \mathrm{M}$ Gharavi. ${ }^{1}$ Department of Midwifery, Mashhad University of Medical Sciences, Mashahd, Khorasan Razavi, Iran; ${ }^{2}$ Department of Obstetrics \& Gynaecology, Mashhad University of Medical Sciences, Mashahd, Khorasan Razavi, Iran; ${ }^{3}$ Department of Psychology, Mashhad University of Medical Sciences, Mashahd, Khorasan Razavi, Iran

Introduction Infertility is an acute life crisis with psychological consequences which may last for an indeterminate length of time and one of the greatest challenges of infertile women is coping with this crisis. The present study was designed to examine the effect of collaborative counselling model on stress and coping strategies in infertile women undergoing IVF in 2010 in Iran.

Methods In this clinical trial, 60 women with primary infertility were randomly selected from Montaserieh Research Centre in Mashhad and were allocated to intervention and control groups. Women in intervention group were counselled in five meetings with collaboration of midwife, gynaecologist and clinical psychologist. Control group received routine cares. Infertility-related stress and coping strategies were measured at the beginning and embryo transfer day using Fertility Problem Inventory and Ways of Coping questionnaire. Data were analysed using statistical tests including $t$ test and Mann-Whitney.

Results A significant difference was found between two groups in terms of total perceived infertility-related stress score $(p<0.048)$. The amount of stress reduction in intervention group was nearly 3.6 times of control group. There was also a significant difference between two groups in terms of problem focused coping strategies $(p<0.003)$. Infertile women used more focused coping strategies in comparison to emotional focused coping strategies.

Conclusion Conducting collaborative counselling can decrease infertile women's perceived stress and increase the use of problem focused coping strategies. It is therefore recommended to use collaborative counselling approaches in order to help infertile women better come to terms with their stressful situation. 